\title{
Relationship between HIV serostatus, CD4 count and rehospitalisation: Potential implications for health systems strengthening in South Africa
}

\author{
Yoshan Moodley ${ }^{a, *}$ and Andrew Tomita ${ }^{b}$ \\ ${ }^{a}$ Discipline of Anaesthesiology and Critical Care Medicine, University of KwaZulu-Natal, Durban, South Africa \\ ${ }^{b}$ Africa Centre for Health and Population Studies, University of KwaZulu-Natal, Durban, South Africa \\ *Corresponding author, email: moodleyyo@ukzn.ac.za
}

Background: Despite three decades of scientific response to HIV/AIDS, the generalised HIV epidemic continues to persist in South Africa. There is growing acknowledgement that health system strengthening will be critical in tackling HIV/AIDS. Patient rehospitalisation is an important quality benchmark of health service delivery, but there is currently limited data on rehospitalisation of patients with HIV/AIDS in South Africa, a setting with a high burden of HIV disease.

Objectives: To determine the relationship between combined HIV serostatus and CD4 count, and rehospitalisation in South Africa.

Methods: This study was a retrospective analysis of data from 11,362 non-surgical adult patients who attended the Hlabisa Hospital in South Africa. Data related to patient age, gender, HIV serostatus, CD4 count (for HIV-positive patients) and comorbidity were analysed through univariate (Fisher's Exact or $\chi^{2}$ tests) and multivariate (Cox regression) statistical methods to determine associations with rehospitalisation within 1 month (acute rehospitalisation) or 12 months (long term rehospitalisation).

Results: An HIV-positive serostatus with CD4 count $<350$ cells $/ \mathrm{mm}^{3}$ or an HIV-positive serostatus with an unknown CD4 count were independently associated with a higher risk of acute $(p=0.010$ and $p=0.003)$ and long term rehospitalisation $(p<0.001$ for both categories) when compared with an HIV-negative serostatus group.

Conclusions: HIV-positive individuals with immune deficiency, or lacking a CD4 count measurement are at risk of rehospitalisation. Strengthening primary healthcare service delivery of these key affected inpatient populations should be a priority.

Keywords: CD4 count, HIV, patient re-admission, rehospitalisation, serostatus

\section{Introduction}

Southern Africa is considered the epicenter of the global HIV epidemic with 6.4 million people living with the disease in South

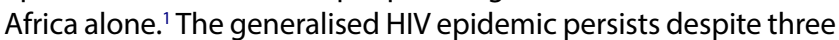
decades of scientific response to HIV/AIDS. There is growing acknowledgement that health system performance will be critical, particularly in public hospital settings where the disease burden related to HIV infection is often high. ${ }^{2}$ In the KwaZuluNatal province of South Africa, HIV has placed significant strain on health service resources. ${ }^{3}$ There is an urgent need to identify ways in which public hospitals can provide optimal quality care for HIV/ AIDS patients. Reducing patient rehospitalisation is not only a financial imperative, but also a potentially important benchmark for quality of care performance within healthcare facilities. Indeed, rehospitalisation has been included as an adverse outcome in the World Health Organisation's "Performance Assessment tool for Quality Improvement in Hospitals", ${ }^{4}$ signifying its importance related to measuring healthcare quality at a global level. Stanley et al., also note that rehospitalisation is a potential marker of inefficiencies in the overall health system in South Africa where the high burden of HIV-related disease exacerbates bed shortages within public healthcare facilities. ${ }^{5}$ Instituting such a benchmark is understood to encourage an improvement in care transition and mitigation of potential risks, thereby reducing the number of patients requiring rehospitalisation. While rehospitalisation has not been used as benchmark for quality of care in South African HIV-infected patients, it has been used in American studies of HIV-infected populations. ${ }^{6,7}$

Determining HIV serostatus and CD4 count measurements are critical for long term patient care/management. ${ }^{8}$ In addition, HIV serostatus and CD4 count are also independent predictors of rehospitalisation.${ }^{6,9}$ However, little is known about the relationship between HIV serostatus, CD4 count, and rehospitalisation in South Africa. Considering the high burden of HIV infection in South Africa and the widely practiced "opt-in" approach to HIV counselling and testing (HCT), ${ }^{10}$ it is likely that an HIV-positive serostatus (and possible low CD4 counts) might be missed in a number of patients who do not consent to HCT. Undiagnosed HIV infection and possible immunodeficiency in patients who are actually HIV-positive hinders linkages to appropriate treatment, representing a missed opportunity to prevent future HIV transmission. This study sought to determine the relationship between combined HIV serostatus and CD4 count, and its relationship to rehospitalisation in a South African setting.

\section{Methods}

\section{Study design, setting, data source, and outcome definitions}

This study was a retrospective analysis of data collected by the Africa Centre Demographic Information System (ACDIS), ${ }^{11}$ and involved 11,362 unique adult patients who were admitted to the Hlabisa Hospital in South Africa for medical (non-surgical) reasons between October 2009 and February 2014. The Hlabisa hospital provides services at the primary healthcare level to residents of Hlabisa, Mtubatuba and parts of the "big five" municipalities in northern KwaZulu-Natal province, South Africa. The general population of the Hlabisa district has been described in detail elsewhere. ${ }^{11}$ The overall incidence of HIV in the Hlabisa district has been estimated at 3.2/100 person years. ${ }^{11}$ Briefly, data related to age, gender, and HIV serostatus (HIV-positive, HIVnegative, or HIV-unknown) were extracted from the ACDIS dataset for each patient at the index hospital admission, and 
defined as the first recorded hospital admission for the patient that was within the data collection timeframe for this study. For patients with a recorded HIV-positive serostatus, data related to CD4 count measurements (categorised as " $<350$ cells $/ \mathrm{mm}^{3}$ ",

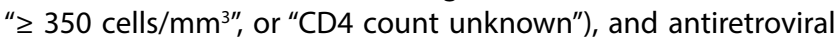
therapy (ART) prescription (categorised as "yes", "no", or "unknown") was also collected. A set of ICD-10 codes were used to identify the presence of comorbidities potentially associated with rehospitalisation for each patient. $^{12}$ The relationship between these comorbid conditions and a higher risk of rehospitalisation has been described elsewhere. ${ }^{13}$ In lieu of current estimates for the burden of tuberculosis (TB) infection in Africa, we also decided to investigate the potential impact of TB infection on rehospitalisation. ${ }^{14} \mathrm{~A}$ patient was considered rehospitalised within 1 month (acute rehospitalisation) or 12 months (long term rehospitalisation) if a second hospital admission was recorded for the patient within the aforementioned time periods following their index hospital admission. Rehospitalisation events which fell outside of the 1 or 12 month time period were censored for each time period analysis. Data related to second rehospitalisations were not analysed in this study. Furthermore, reasons for rehospitalisation were also not analysed in this study. This study was approved by the Biomedical Research Ethics Committee of the University of KwaZulu-Natal, South Africa (Protocol EXM277/15).

\section{Statistical analysis}

Separate statistical analyses were performed for each outcome investigated in this study (acute and long term rehospitalisation). Age data was analysed via a Mann-Whitney U test. Gender, CD4 count categories, and comorbidity data were analysed using Fisher's Exact or $\chi^{2}$ tests, where appropriate. Variables attaining a $p$-value $<0.2$ from the aforementioned univariate analyses were purposefully selected for inclusion in a Cox regression model. Results for the Cox regression analyses are presented as hazard ratio's (HR) with $95 \%$ confidence intervals $(95 \% \mathrm{Cl})$. A $p$-value $<0.05$ was considered statistically significant. All data analysis was conducted using the Statistical Package for the Social Sciences (SPSS) Version 23 (IBM Corporation, USA).

\section{Results}

\section{Sample demographic and clinical characteristics (Entire cohort)}

Demographic and clinical characteristics for the entire study cohort are shown in Table 1. The median age of the entire cohort was 34.0 (interquartile range: $26.0-50.0$ ) years. Males comprised $38.9 \%$ of the entire cohort. The percentage of patients in the entire cohort which fell within each HIV serostatus and CD4 count category were as follows: HIV-positive serostatus with CD4 count $<350$ cells/ $\mathrm{mm}^{3}=5.1 \%$; HIV-positive serostatus with CD4 count $\geq 350$ cells/ $\mathrm{mm}^{3}=1.8 \%$; HIV-positive serostatus with unknown CD4 count $=29.5 \%$; HIV-negative serostatus $=9.7 \%$; and, HIV serostatus unknown $=53.9 \%$. The percentage of patients in the entire cohort which fell within each HIV serostatus-ART category were as follows: HIV-positive serostatus, no ART = 19.8\%; HIV-positive serostatus with ART = 16.4\%; HIV-positive serostatus, ART unknown $=0.2 \%$; HIV-negative serostatus, no ART $=9.7 \%$; and, HIV serostatus unknown, no ART $=53.9 \%$. Tuberculosis, uncomplicated diabetes, and renal disease were the three most prevalent comorbidities observed at the index hospital admission (Table 1). The percentage of patients in the entire cohort rehospitalised within 1 month or 12 months from an index hospital admission was $3.8 \%$ and $12.5 \%$, respectively.

\section{Sample demographic and clinical characteristics (Stratified by rehospitalisation status)}

Demographic and clinical characteristics for the entire cohort stratified by rehospitalisation status are also shown in Table 1. The median age of patients with long term rehospitalisation was significantly older than that for patients without long term rehospitalisation $(p<0.001)$. A statistical trend toward rehospitalisation in older patients was also observed for acute rehospitalisation ( $p=0.058$ ). Male gender was statistically associated with long term rehospitalisation $(p<0.001)$, but not acute rehospitalisation ( $p=0.182$ ). Overall, HIV serostatus-CD4 count appeared to be associated with acute and long term rehospitalisation ( $p=0.003$ and $p<0.001$, respectively). Similarly, HIV-serostatus-ART status also appeared to be associated with acute and long term rehospitalisation ( $p=0.006$ and $p<0.001$, respectively). Not all of the established comorbidities associations with acute or long term rehospitalisation were univariate in this study (Table 1).

\section{Cox regression analyses}

The results of the Cox regression analyses are shown in Table 2. When compared with the HIV-negative serostatus group, an HIVpositive serostatus with a CD4 count $<350$ cells $/ \mathrm{mm}^{3}$ or an HIVpositive serostatus with an unknown CD4 count were independent predictors of acute $(p=0.010$ and $p=0.003$, respectively) and long term ( $p<0.001$ for both CD4 categories) rehospitalisation. Non-statistically significant increases in risk were noted for patients with an HIV-positive serostatus with a CD4 count $\geq 350$ cells $/ \mathrm{mm}^{3}$ or an HIV-unknown serostatus (Table 2). Similarly, when compared with the HIV-negative, no ART group, HIV-positivity with ART or HIV-positivity without ART were independent predictors of acute $(p=0.004$ and $p=0.006$, respectively) and long term ( $p<0.001$ for both ART categories) rehospitalisation. Of the remaining ART categories, only HIVunknown with no ART was independently associated with rehospitalisation (long term only, $p=0.031$ ). Male gender and age were found to be independent predictors of long term rehospitalisation ( $p=0.015$ and $p<0.001$, respectively). Nonmetastatic malignancy and uncomplicated diabetes were the only two comorbid conditions which were independently associated with acute rehospitalisation, while the importance of comorbidities such as congestive heart failure and mild liver disease was noted for the long term rehospitalisation (Table 2). Tuberculosis with either an HIV-positive or HIV-negative serostatus was independently associated with a higher risk of long term rehospitalisation only $(p=0.001$ and $p=0.043$, respectively). A non-statistically significant trend toward a higher risk of long term rehospitalisation in tuberculosis patients with unknown HIV-serostatus was also noted (Table 2).

\section{Discussion}

\section{Impact of HIV serostatus and CD4 count on rehospitalisation}

While the uptake of HIV testing in this study might appear low (only $46.1 \%$ of the study population had a known HIV status despite the high burden of HIV infection in Hlabisa), the uptake levels of HIV testing observed in this research lie within the estimates of $38 \%$ and $58 \%$, which have previously been reported for the general population of Hlabisa. ${ }^{11}$ We found a two-fold increase in risk for acute rehospitalisation in patients who had an HIV-positive serostatus with a CD4 count $<350$ cells $/ \mathrm{mm}^{3}$ or an HIV-positive serostatus with an unknown CD4 count. Significantly higher risk in the aforementioned HIV serostatus or CD4 count categories was also noted for long term rehospitalisation. A non-statistically 
Table 1: Characteristics of the study population (stratified by rehospitalisation status) expressed as a frequency (\%)

\begin{tabular}{|c|c|c|c|c|c|c|c|c|c|}
\hline \multirow[b]{2}{*}{ Characteristic } & \multirow[b]{2}{*}{$\begin{array}{c}\text { Major } \\
\text { Category }\end{array}$} & \multirow[b]{2}{*}{$\begin{array}{c}\text { Sub- } \\
\text { Category }\end{array}$} & \multirow[b]{2}{*}{$\begin{array}{c}\text { Entire } \\
\text { Cohort } \\
(n=11362)\end{array}$} & \multicolumn{3}{|c|}{ Acute rehospitalisation } & \multicolumn{3}{|c|}{ Long term rehospitalisation } \\
\hline & & & & $\begin{array}{l}\text { Patients with } \\
\text { Rehospitalisation } \\
\qquad(n=431)\end{array}$ & $\begin{array}{l}\text { Patients without } \\
\text { Rehospitalisation } \\
\qquad(n=10931)\end{array}$ & $\begin{array}{c}\boldsymbol{p} \text { - } \\
\text { value }\end{array}$ & $\begin{array}{l}\text { Patients with } \\
\text { Rehospitalisation } \\
\qquad(n=1420)\end{array}$ & $\begin{array}{l}\text { Patients without } \\
\text { Rehospitalisation } \\
\qquad(n=9942)\end{array}$ & $p$-value \\
\hline $\begin{array}{l}\text { Median Age in } \\
\text { years (IQR) }\end{array}$ & - & - & $\begin{array}{c}34.0(26.0- \\
50.0)\end{array}$ & $36.0(28.0-49.0)$ & $34.0(26.0-50.0)$ & 0.058 & $39.0(29.0-56.0)$ & $34.0(25.0-49.0)$ & $<0.001$ \\
\hline Male Gender & - & - & $\begin{array}{l}4422 \\
(38.9)\end{array}$ & $181(42.0)$ & $4241(38.8)$ & 0.182 & $612(43.1)$ & $3810(38.3)$ & 0.001 \\
\hline \multirow[t]{6}{*}{ HIV serostatus } & & & & & & 0.003 & & & $<0.001$ \\
\hline & Negative & - & $1102(9.7)$ & $27(6.3)$ & $1075(9.8)$ & & $92(6.5)$ & $1010(10.2)$ & \\
\hline & Positive & $\begin{array}{l}\text { CD4 } \\
\text { count } \\
<350 \\
\text { cells/ } \\
\mathrm{mm}^{3}\end{array}$ & $579(5.1)$ & $28(6.5)$ & $551(5.0)$ & & $90(6.3)$ & $489(4.9)$ & \\
\hline & & $\begin{array}{l}\text { CD4 } \\
\text { count } \\
\geq 350 \\
\text { cells/ } \\
\mathrm{mm}^{3}\end{array}$ & $209(1.8)$ & $5(1.2)$ & $204(1.9)$ & & $25(1.8)$ & $184(1.9)$ & \\
\hline & & $\begin{array}{c}\text { CD4 } \\
\text { count } \\
\text { unknown }\end{array}$ & $\begin{array}{l}3349 \\
(29.5)\end{array}$ & $155(36.0)$ & $3194(29.2)$ & & $508(35.8)$ & $2841(28.6)$ & \\
\hline & Unknown & - & $\begin{array}{l}6123 \\
(53.9)\end{array}$ & $216(50.1)$ & $5907(52.0)$ & & $705(49.6)$ & $5418(54.5)$ & \\
\hline \multirow{6}{*}{$\begin{array}{l}\text { Antiretroviral } \\
\text { Therapy (ART) }\end{array}$} & & 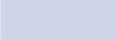 & & & & 0.006 & & & $<0.001$ \\
\hline & $\begin{array}{l}\text { HIV-neg- } \\
\text { ative (No } \\
\text { ART) }\end{array}$ & - & $1102(9.7)$ & $27(6.3)$ & $1075(9.8)$ & & $92(6.5)$ & $1010(10.2)$ & \\
\hline & $\begin{array}{l}\text { HIV-posi- } \\
\text { tive }\end{array}$ & No & $\begin{array}{l}2254 \\
(19.8)\end{array}$ & $99(23.0)$ & $2155(19.7)$ & & $314(22.1)$ & 1940 (19.5) & \\
\hline & & Unknown & $20(0.2)$ & $1(0.2)$ & $19(0.2)$ & & $1(0.1)$ & $19(0.2)$ & \\
\hline & & Yes & $\begin{array}{l}1863 \\
(16.4)\end{array}$ & $88(20.4)$ & $1775(16.2)$ & & $308(21.7)$ & 1555 (15.6) & \\
\hline & $\begin{array}{l}\text { HIV-un- } \\
\text { known } \\
\text { (No ART) }\end{array}$ & - & $\begin{array}{l}6123 \\
(53.9)\end{array}$ & $216(50.1)$ & $5907(54.0)$ & & 705 (49.6) & $5418(54.5)$ & \\
\hline $\begin{array}{l}\text { Congestive } \\
\text { heart failure }\end{array}$ & - & - & $350(3.1)$ & $19(4.4)$ & $331(3.0)$ & 0.104 & $83(5.8)$ & $267(2.7)$ & $<0.001$ \\
\hline $\begin{array}{l}\text { Connective } \\
\text { tissue disease }\end{array}$ & - & - & $4(<0.1)$ & $0(0.0)$ & $4(<0.1)$ & 0.999 & $1(0.1)$ & $3(<0.1)$ & 0.414 \\
\hline $\begin{array}{l}\text { Chronic } \\
\text { obstructive } \\
\text { pulmonary } \\
\text { disease }\end{array}$ & - & - & $87(0.8)$ & $5(1.2)$ & $82(0.8)$ & 0.387 & $16(1.1)$ & $71(0.7)$ & 0.095 \\
\hline $\begin{array}{l}\text { Cerebrovascu- } \\
\text { lar disease }\end{array}$ & - & - & $12(0.1)$ & $0(0.0)$ & $12(0.1)$ & 0.999 & $1(0.1)$ & $11(0.1)$ & 0.999 \\
\hline Dementia & - & - & $27(0.2)$ & $0(0.0)$ & $27(0.2)$ & 0.625 & $7(0.5)$ & $20(0.2)$ & 0.071 \\
\hline $\begin{array}{l}\text { Complicated } \\
\text { diabetes }\end{array}$ & - & - & $62(0.5)$ & $3(0.7)$ & $59(0.5)$ & 0.510 & $14(1.0)$ & $48(0.5)$ & 0.016 \\
\hline $\begin{array}{l}\text { Uncomplicat- } \\
\text { ed diabetes }\end{array}$ & - & - & $598(5.3)$ & $31(7.2)$ & $567(5.2)$ & 0.067 & $110(7.7)$ & $488(4.9)$ & $<0.001$ \\
\hline $\begin{array}{l}\text { Hemiplegia or } \\
\text { paraplegia }\end{array}$ & - & - & $72(0.6)$ & $5(1.2)$ & $67(0.6)$ & 0.199 & $13(0.9)$ & $59(0.6)$ & 0.153 \\
\hline $\begin{array}{l}\text { Metastatic } \\
\text { malignancy }\end{array}$ & - & - & $1(<0.1)$ & $0(0.0)$ & $1(<0.1)$ & 0.999 & $0(0.0)$ & $1(<0.1)$ & 0.999 \\
\hline $\begin{array}{l}\text { Myocardial } \\
\text { infarction }\end{array}$ & - & - & $0(0.0)$ & $0(0.0)$ & $0(0.0)$ & * & $0(0.0)$ & $0(0.0)$ & * \\
\hline $\begin{array}{l}\text { Mild liver } \\
\text { disease }\end{array}$ & - & - & $31(0.3)$ & $2(0.5)$ & $29(0.3)$ & 0.330 & $9(0.6)$ & $22(0.2)$ & 0.011 \\
\hline
\end{tabular}




\begin{tabular}{|c|c|c|c|c|c|c|c|c|c|}
\hline \multirow[b]{2}{*}{ Characteristic } & \multirow[b]{2}{*}{$\begin{array}{l}\text { Major } \\
\text { Category }\end{array}$} & \multirow[b]{2}{*}{$\begin{array}{c}\text { Sub- } \\
\text { Category }\end{array}$} & \multirow[b]{2}{*}{$\begin{array}{c}\text { Entire } \\
\text { Cohort } \\
(n=11362)\end{array}$} & \multicolumn{3}{|c|}{ Acute rehospitalisation } & \multicolumn{3}{|c|}{ Long term rehospitalisation } \\
\hline & & & & $\begin{array}{l}\text { Patients with } \\
\text { Rehospitalisation } \\
(n=431)\end{array}$ & $\begin{array}{l}\text { Patients without } \\
\text { Rehospitalisation } \\
\quad(n=10931)\end{array}$ & $\begin{array}{c}p \text { - } \\
\text { value }\end{array}$ & $\begin{array}{l}\text { Patients with } \\
\text { Rehospitalisation } \\
(n=1420)\end{array}$ & $\begin{array}{l}\text { Patients without } \\
\text { Rehospitalisation } \\
\qquad(n=9942)\end{array}$ & $p$-value \\
\hline $\begin{array}{l}\text { Moderate or } \\
\text { severe liver } \\
\text { disease }\end{array}$ & - & - & $12(0.1)$ & $0(0.0)$ & $12(0.1)$ & 0.999 & $1(0.1)$ & $11(0.1)$ & 0.999 \\
\hline $\begin{array}{l}\text { Non-metastat- } \\
\text { ic malignancy }\end{array}$ & - & - & $196(1.7)$ & $23(5.3)$ & $173(1.6)$ & $<0.001$ & $67(4.7)$ & $129(1.3)$ & $<0.001$ \\
\hline Peptic ulcer & - & - & $67(0.6)$ & $2(0.5)$ & $65(0.6)$ & 0.999 & $13(0.9)$ & $54(0.5)$ & 0.086 \\
\hline $\begin{array}{l}\text { Peripheral vas- } \\
\text { cular disease }\end{array}$ & - & - & $5(<0.1)$ & $0(0.0)$ & $5(<0.1)$ & 0.999 & $1(0.1)$ & $4(<0.1)$ & 0.487 \\
\hline Renal disease & - & - & $268(2.4)$ & $14(3.2)$ & $254(2.3)$ & 0.215 & $42(3.0)$ & $226(2.3)$ & 0.112 \\
\hline \multirow[t]{5}{*}{ Tuberculosis } & & & & & & 0.807 & & & $<0.001$ \\
\hline & No & - & $\begin{array}{c}9172 \\
(80.7)\end{array}$ & $342(79.4)$ & $8830(80.8)$ & & $1070(75.4)$ & $8102(81.5)$ & \\
\hline & Yes & $\begin{array}{l}\text { HIV-nega- } \\
\text { tive }\end{array}$ & $138(1.2)$ & $7(1.6)$ & $131(1.2)$ & & $24(1.7)$ & $114(1.1)$ & \\
\hline & & $\begin{array}{l}\text { HIV-posi- } \\
\text { tive }\end{array}$ & $\begin{array}{c}1613 \\
(14.2)\end{array}$ & $65(15.1)$ & $1548(14.2)$ & & $265(18.7)$ & $1348(13.6)$ & \\
\hline & & $\begin{array}{l}\text { HIV-un- } \\
\text { known }\end{array}$ & 439 (3.9) & $17(3.9)$ & $422(3.9)$ & & $61(4.3)$ & $378(3.8)$ & \\
\hline
\end{tabular}

Note: ART: Antiretroviral therapy.

*Unable to compute.

significant increase in risk for the CD4 count $\geq 350$ cells $/ \mathrm{mm}^{3}$ group was noted for acute and long term rehospitalisation $(H R>1.0$, but did not reach statistical significance). The findings for the aforementioned HIV serostatus or CD4 count categories is similar to the findings of Berry et al., who found that any positive HIV serostatus (irrespective of CD4 count) is potentially associated with a higher risk of rehospitalisation. ${ }^{6}$ This study did not establish an independent association between an unknown HIV serostatus and a higher risk of acute or long term rehospitalisation. However, the risk estimates obtained from the Cox regression analyses suggest a trend toward a harmful association between an unknown HIV serostatus and a higher risk of rehospitalisation (36.3\% higher risk for acute rehospitalisation, and $17.5 \%$ higher risk for long term rehospitalisation). Considering our findings for the HIV-positive serostatus with CD4 count $<350$ cells $/ \mathrm{mm}^{3}$ and the HIV-positive serostatus with unknown CD4 count groups, it is likely that a large proportion of patients with an unknown HIV serostatus in this study were actually HIV-positive. It remains important that in settings with a high burden of HIV infection, every effort should be made to determine HIV serostatus (and also CD4 count) in patients where there is none recorded.

\section{Impact of other clinical factors on rehospitalisation}

Both HIV-infected patients on ART, and HIV-infected patients not on ART experienced an almost 2-fold higher risk of acute and long term rehospitalisation. This finding is in disagreement with the findings of a matched cohort study conducted by Nosyk et al., ${ }^{15}$ which reported a $28 \%$ lower readmission rate in HIV-infected patients receiving ART when compared with HIV-infected patients who were not receiving ART. Important to note, however, the study of Nosyk and colleagues ${ }^{15}$ was conducted in a low-burden tuberculosis setting (Canada), when compared with our study setting. It is possible that a higher burden of latent tuberculosis and subsequent immune reconstitution inflammatory syndrome in patients on ART in our setting may account for the high rate of rehospitalisation in this group. This is supported by the findings of our research which show a higher risk of rehospitalisation (long term) in tuberculosis patients with HIV versus tuberculosis patients without HIV.

We also found age and gender to be independently associated with rehospitalisation. The findings for age in keeping with the majority of published studies which had sought to develop models to predict rehospitalisation. ${ }^{16}$ We found that the male gender was associated with a higher risk of rehospitalisation, which is in agreement with a British study by Woz and colleagues. ${ }^{17}$ In that study, hospital utilisation in the 6 months prior to the index hospitalisation, being unmarried, having a positive depression screen and no primary care physician visit within 30 days, were identified as major risk factors for rehospitalisation in males (versus females). ${ }^{17}$ There is a lack of gender-specific data related to risk factors for all-cause rehospitalisation in a South African setting, and it is therefore unknown whether the risk factors identified in the study of Woz et al., ${ }^{17}$ would still be applicable in this setting. Further research investigating risk factors for higher rehospitalisation in males versus females in this setting is required.

A number of the comorbid diseases associated with a higher risk of rehospitalisation elsewhere ${ }^{13}$ were not identified as risk factors for rehospitalisation in this study. This finding might be related to the current epidemiological transition being experienced in South Africa, ${ }^{18}$ as opposed to the burden of non-communicable disease versus communicable disease in countries from which the established risk factors are reported. This difference is further highlighted by our findings for TB infection.

\section{Study limitations}

This study had several limitations. Firstly, this is a subanalysis of data collected from a single healthcare facility, and therefore the findings of this study might not be applicable to the greater HIVinfected population. Secondly, we did not present data related to viral load in the HIV-infected population as these data were not available. Finally, we were unable to investigate the potential importance of any inpatient hospital laboratory results (besides 
Table 2: Results of the Cox regression analysis

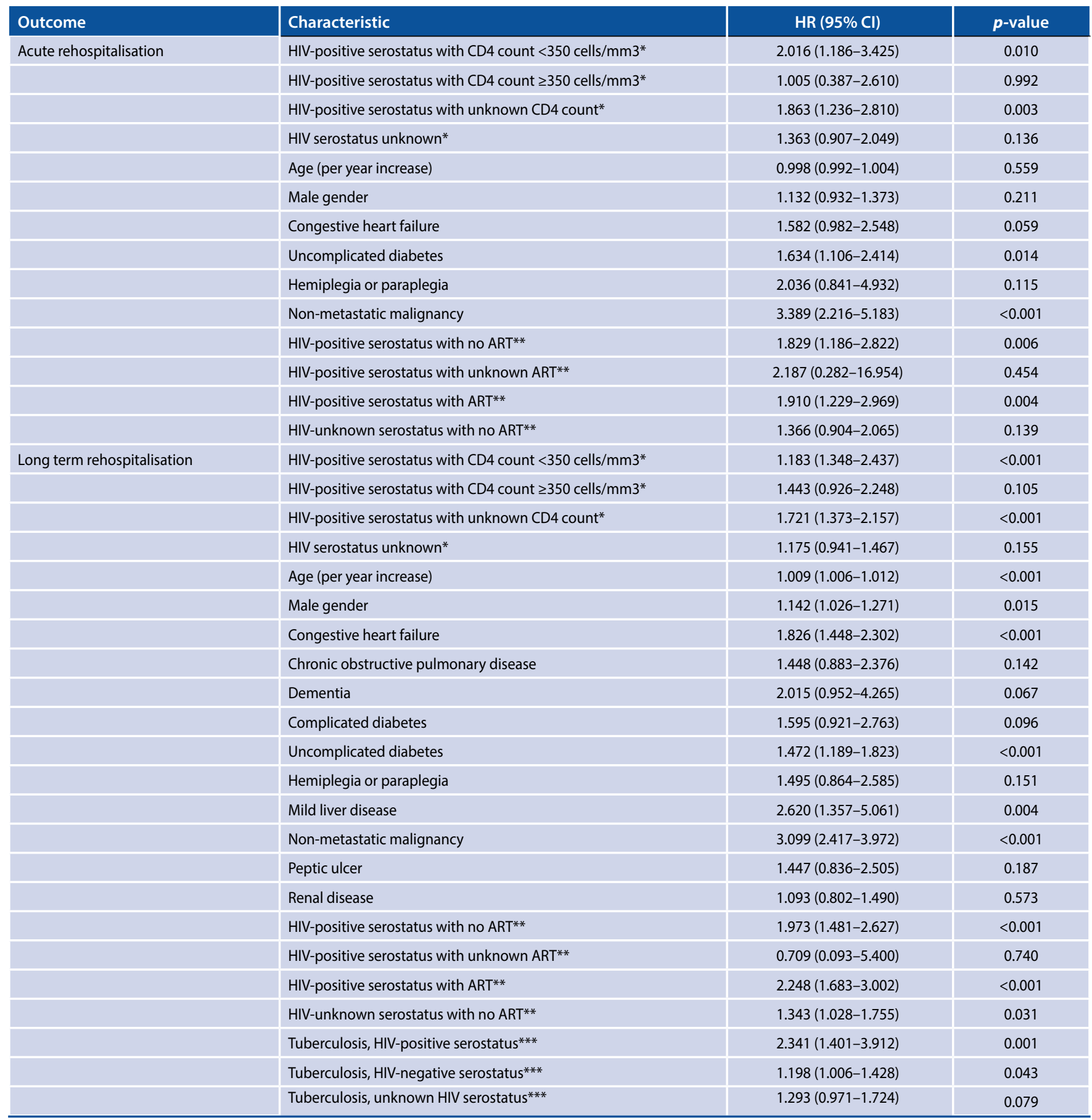

Notes: ART: Antiretroviral therapy; HR: Hazard ratio.

*When compared with reference group: HIV-negative serostatus.

**When compared with reference group: HIV-negative (No ART).

***When compared with reference group: No Tuberculosis.

CD4 count) in this study as these data was not collected as part of the ACDIS. Although this study does have limitations, it nevertheless presents important data related to HIV status and acute or long term rehospitalisation events from a setting with a high burden of HIV infection.

\section{Conclusion}

In summary, we found independent associations between some combined HIV serostatus or CD4 count categories (HIV-positive serostatus with a CD4 count $<350$ cells $/ \mathrm{mm}^{3}$ or an HIV-positive serostatus with an unknown CD4 count) and a higher risk of acute and long term rehospitalisation. There were nonstatistically significant trends toward a higher risk of acute and long term rehospitalisation observed for some categories (HIVpositive serostatus group with CD4 count $\geq 350$ cells $/ \mathrm{mm}^{3}$ or unknown HIV serostatus group). Although further research is required to confirm the findings of our study, it highlights the potential importance of strengthening primary healthcare service delivery for HIV-infected patients with low CD4 counts, or patients with missing HIV serostatus and CD4 counts. 
Acknowledgements - YM was supported by a postdoctoral fellowship awarded by the South African National Research Foundation (NRF). AT was supported by SA MRC Flagship grant (MRC-RFAUFSP-01-2013/UKZN HIVEPI) and National Institutes of Health Research Training Grant (R25TW009337), funded by the Fogarty International Center and the National Institute of Mental Health.

The content is solely the responsibility of the authors and does not necessarily represent the official views of the NRF, the MRC, or the $\mathrm{NIH}$.

Funding source - YM was supported by a postdoctoral fellowship awarded by the South African National Research Foundation (NRF). AT was supported by SA MRC Flagship grant (MRC-RFAUFSP-01-2013/UKZN HIVEPI) and National Institutes of Health Research Training Grant (R25TW009337), funded by the Fogarty International Center and the National Institute of Mental Health.

Conflicts of Interest - None declared.

\section{References}

1. Shisana O, Rehle T, Simbayi LC, Zuma K, et al. South African national HIV prevalence, incidence and behaviour survey, 2012. Cape Town: HSRC Press; 2014.

2. Marchal B, Brouwere V, Kegels G. Viewpoint: HIV/AIDS and the health workforce crisis: what are the next steps? Trop Med Int Health. 2005;10(4):300-4.

3. Parikh A, Veenstra N. The evolving impact of HIV/AIDS on outpatient health services in Kwazulu-Natal. South Africa. S Afr Med J. 2008;98(6):468-72.

4. Groene O, Klazinga N, Kazandjian V, et al. The World Health Organization performance assessment tool for quality improvement in hospitals (PATH): An analysis of the pilot implementation in 37 hospitals. Int J Qual Health Care. 2008;20(3):155-61.

5. Stanley A, Graham N, Parrish A. A review of internal medicine readmissions in a peri-urban South African hospital. S Afr Med J. 2008;98(4):291-4.

6. Berry SA, Fleishman JA, Moore RD, et al. Thirty-day hospital readmissions for adults with and without HIV infection. HIV Med. 2015.
Availablefrom:http://onlinelibrary.wiley.com/doi/10.1111/hiv.12287/ abstract;jsessionid=10FBA7A31DF1C0E230C93945A00CDFE8.f02t03

7. Feller DJ, Akiyama MJ, Gordon P, et al. Readmissions in HIV-infected inpatients. J Acquir Immune Defic Syndr. 2016;71(4):407-12.

8. Liechty CA. The evolving role of HIV counseling and testing in resource-limited settings: HIV prevention and linkage to expanding HIV care access. Curr HIV/AIDS Rep. 2004;1(4):181-5.

9. Crum-Cianflone NF, Grandits G, Echols S, et al. Trends and causes of hospitalizations among HIV-infected persons during the late HAART era: what is the impact of CD4 counts and HAART use? J Acquir Immune Defic Syndr. 2010;54(3):248-57.

10. Baisley K, Doyle AM, Changalucha J, et al. Uptake of voluntary counselling and testing among young people participating in an HIV prevention trial: comparison of opt-out and opt-in strategies. PLoS ONE 2012;7(7):e42108.

11. Tanser F, Hosegood V, Barnighausen T, et al. Cohort profile: Africa centre demographic information system (ACDIS) and populationbased HIV survey. Int J Epidemiol. 2008;37(5):956-62.

12. Quan $\mathrm{H}$, Sundararajan $V$, Halfon $P$, et al. Coding algorithms for defining comorbidities in ICD-9-CM and ICD-10 administrative data. Med Care. 2005;43(11):1130-9.

13. Alonso-Morán E, Nuño-Solinis R, Onder G, et al. Multimorbidity in risk stratification tools to predict negative outcomes in adult population. Eur J Intern Med. 2015;26(3):182-9.

14. Murray CJ, Ortblad KF, Guinovart C, et al. Global, regional, and national incidence and mortality for HIV, tuberculosis, and malaria during 1990-2013: a systematic analysis for the Global Burden of Disease Study 2013. Lancet. 2014;384(9947):1005-70.

15. Nosyk B, Sun H, Li X, et al. Highly active antiretroviral therapy and hospital readmission: comparison of a matched cohort. BMC Infect Dis. 2006;6:146.

16. Kansagara D, Englander $H$, Salanitro A, et al. Risk prediction models for hospital readmission. JAMA. 2011;306(15):1688-98.

17. Woz S, Mitchell S, Hesko C, et al. Gender as risk factor for 30 days postdischarge hospital utilisation: a secondary data analysis. BMJ Open. 2012;2(2):e000428.

18. Kahn K. Population health in South Africa: dynamics over the past two decades. J Public Health Policy. 2011;32(S1):S30-6.

Received: 21-12-2015 Accepted: 10-06-2016 